1. Arquitecto, investigador del Conicet (Consejo de Investigaciones Científicas de Argentina), académico de Número de la Academia de la Historia y de la Academia de Bellas Artes de Argentina, director del Centro de Documentación de Arquitectura Latinoamericana (Cedodal) con sede en Buenos Aires. 


\title{
LOS CENTROS HISTÓRICOS DE IBEROAMERICA. POLÍTICAS Y IMPROVISACIONES
}

HISTORICAL CENTERS OF IBERO-AMERICA.

POLICIES AND IMPROVISATIONS

Ramón Gutiérrez

\begin{abstract}
This is a review of the policies formulated for the conservation of historical centers of the continent since the second half of the $20^{\text {th }}$ century. It analyses the criteria for the definition of centers based on the set of "monumental works", their insertion into the planning, and the passage from punctual reading to the whole set. It focuses on the ideas of a more complex view, so as to include social themes side by side with cultural ones, and of a definition of housing policies to improve the conditions of abandoned or degraded areas. It also considers the role of tourism as a dynamic element and the risks of disregarding the inhabitants in face of major inversions. The review of historical centers in the integrating perspective of the concept of "cultural landscape" empowers the sense of citizenship and assures more efficient policies and actions.
\end{abstract}

Key words: Historical centers; Cultural landscape; Tourism; Social housing. 


\section{Antecedentes (1950-1980)}

\section{Las estrategias de intervención}

Las primeras acciones encaradas en los Centros Históricos de América Latina derivan de las experiencias de la reconstrucción europea de posguerra. Podemos señalar algunas tendencias dominantes: a) Las ciudades-Museo como las actuaciones en San Juan de Puerto Rico (1955) y Antigua Guatemala (1958), b) La ciudad-dormitorio para una población externa de altos recursos que "compra" un poblado histórico, tal el caso de Colonia del Sacramento (Uruguay) o Paratí (Brasil) y c) Rescate en función del turismo, como en el Plan Copesco del Perú.

Estas acciones se basaban en general en la identificación de "monumentos" puntuales, cuya envolvente de localización definía el "área histórica". El concepto de lo "histórico" recién devino en una ampliación "cultural" en la década de los 70, esto significó pasar de los monumentos a obras de otro nivel, pero que tenían un sentido significativo en la sociedad. En general estas intervenciones fueron realizadas pensando en una población ajena al propio Centro Histórico.

Ello fue así tanto en los casos de ciudades donde el centro histórico había sido abandonado por la población original y ocupado por sectores de bajos recursos (Cusco, Quito, Lima etc) como en otros donde permanecía la población pero fue expulsada en función de la renovación (Ciudad-dormitorio) o de la propia estrategia de terciarización (Ciudad-museo).

La intervención de rescate en función del turismo cultural implicó una agresiva política de expulsión poblacional de bajos ingresos para "recuperar" el patrimonio para las nuevas funciones hoteleras como sucedió en el Cusco (1972-80). En otros casos las políticas de renovación urbana significaron no sólo la expulsión de la población sino la destrucción de antiguos barrios para crear nuevos núcleos residenciales de mayores ingresos, tal el caso de Santa Bárbara, hoy "Nueva Santa Fe" en Bogotá.

También podemos incluir en este campo dudosas intervenciones de recuperación del patrimonio, con una fuerte carga de falsificación histórica en las obras realizadas en República Dominicana desde la década del 70, que retrotrayeron partes de la ciudad de Santo Domingo a un hipotético siglo XVI.

Debemos señalar los intentos, posteriormente frustrados, de recuperación de la zona del Pelourinho (Salvador-Bahia, Brasil) mediante una política que intentó articular la recuperación del patrimonio con una dignificación de las condiciones de vida de los habitantes carenciados que lo ocupaban. La falta de continuidad de los apoyos gubernamentales dañaron irreversiblemente una experiencia de suma importancia y abrieron paso a las soluciones de "mercado" que sí contaron con entusiasta apoyo oficial.

\section{Recuperación de áreas históricas y planificación urbana}

Hasta la década de los 70 los planificadores urbanos del continente mantuvieron un rechazo frontal a la inclusión de políticas de preservación en sus planes reguladores o directores. 
Lo "histórico" constituía un capítulo inicial (necesario pero intrascendente) de unas memorias que desembocaban en unos planes que se referían más al modelo prestigiado que a la comprensión profunda de lo que había sido la evolución concreta de la ciudad. No importaba tanto como la ciudad era sino como "debería ser" y eso, obviamente, lo sabía el planificador y no los pobladores.

Fue necesario que algunos planificadores de prestigio y notoria lucidez, como Jorge Enrique Hardoy, llamaran la atención de sus colegas sobre los valores de las áreas centrales y centros históricos del continente, para que se reparara en este sector profesional el extravío u omisión en que se estaba incurriendo. Sin demasiadas convicciones, pero atendiendo al "clima cultural" por un lado y al notorio fracaso de sus proyectos CIAM por el otro, los planificadores rescataron el discurso del "corazón de la ciudad" y fueron paulatinamente apagando sus ínfulas de renovación de "tabula rasa", supermanzanas, zoning rígidos y otros instrumentos que caracterizaron el urbanismo latinoamericano desde 1930 a 1980.

La destrucción de las ciudades latinoamericanas, carentes de protección frente a la especulación inmobiliaria y los planificadores urbanos de la modernidad, fue de una enorme magnitud y ello explica la revalorización que las escasas áreas históricas que permanecen dentro de núcleos de extensa ocupación territorial. Como contrapartida hay ciudades, como San Pablo en Brasil, que se han renovado tres veces en un siglo dejando muy pocas huellas de la ciudad anterior. O el caso de Buenos Aires donde no hay ninguna vivienda que testimonie las tipologías residenciales de los tres primeros siglos de vida de la ciudad.

\section{Políticas y inercias institucionales}

Cuando la difusión del modelo italiano de Bologna alcanzó resonancia, fueron varios los intentos de aplicar unas políticas similares en ciudades americanas. Ya en el Coloquio de Quito (1975), Leonardo Benévolo señalaba las reservas de calidad de vida que podían significar para la futura vida urbana la preservación de estas zonas históricas.

La distancia de las condiciones reales de las ciudades latinoamericanas convertían en una entelequia el intento de trasladar la experiencia italiana. Los aspectos sobresalientes de esta imposibilidad radicaban en el diferente papel del municipio, la incapacidad económica, la presión de los sectores carenciados de vivienda y la falta de organización de la comunidad.

Los municipios son en América débiles frente a la acción de otras esferas del Estado (Federales o Nacionales) cuyas inversiones urbanas son mucho más altas. Son débiles también políticamente frente al poder centralizado y están muy poco organizados para poder actuar técnicamente.

El Cusco, por ejemplo seguía en la década del 80 aplicando un catastro realizado en 1951 y no tenía actualizado ni el padrón de propietarios ni revaluados adecuadamente los bienes. El terremoto de 1987 puso en evidencia la flaqueza del poder municipal cuando muchos vecinos aprovecharon para demoler sus casas 
históricas so pretexto de que estaban dañadas. La contracara es el actual municipio constructor de fuentes, jardines, murales y ornatos de dudoso buen gusto que saturan todos los espacios abiertos. En ambos casos el Alcalde era el mismo, en un caso fue débil y en otro déspota, en ningún momento demostró el equilibrio adecuado para la gestión participativa.

En América las frecuentes dictaduras militares implican que las organizaciones vecinales y comunitarias tengan efímera vida y sean constantemente desalentadas. Por lo tanto la carencia de una estructura orgánica de participación ha paralizado muchos intentos de recuperación de áreas históricas.

La vinculación del tema de los Centros Históricos se desvió entonces del campo de la actuación de un Municipio, que sólo administra la presión de los sectores que actúan sobre la urbe, pero que no fija una política de inducción de la construcción de la ciudad, hacia el sector cultural del Estado.

No podemos dejar de decir que esta ha sido en general una alternativa desafortunada ya que el área cultural es habitualmente muy débil, tanto en recursos cuanto en gravitación política. A la hora de los recortes económicos y los ajustes, el sector cultura es el que cae primero como si se tratara de una inversión a fondo perdido que no se articula en el esquema costo - beneficio.

Ya en la segunda mitad de la década del 70 era clara la imposibilidad de recuperar ningún centro o poblado histórico desde el campo de la cultura si no iba directamente vinculado a una política de recuperación social. La articulación de las políticas de vivienda con la recuperación del patrimonio fueron planteadas en ese momento, pero los intentos en varios países fueron frenados por los intereses de las grandes empresas constructoras que manejan los programas de vivienda popular y a quienes les rendía mucho más la alternativa de obra nueva en las periferias urbanas. Así fracasaron entre otros los proyectos para viviendas en Olinda y San Luis de Marañón en Brasil.

En la década siguiente se aplicaría la anestesia de la Declaratoria de "Patrimonio Cultural de la Humanidad" por la Convención de la Unesco, que habría de generar notorias ilusiones en las decenas de las ciudades incorporadas a esa lista, como si una ciudad pudiera salvarse desde una acción externa que no tuviera a la propia ciudad como protagonista.

\section{Las nuevas condiciones en tiempos de neoliberalismo}

\section{Valorización económica de la ciudad}

En circunstancias en que las propias decisiones políticas se subordinan no ya a la economía, sino a las erráticas "leyes del mercado", la ciudad se ha convertido en un campo, no solamente de conflicto social, sino de enardecida especulación.

Ha desaparecido, en la mayoría de los casos, la noción de "bien común" y los espacios públicos suelen ser enajenados, concedidos para el usufructo de particulares o arrendados para publicidad y otras modalidades de lucro emergente. 
Aún aquellas obras realizadas con cargo a los recursos de la comunidad son cedidas en beneficio de intereses privados que, mediante el sistema de peajes, concesiones o arrendamientos aseguran su mantenimiento y operatividad.

En esta dinámica donde toda la ciudad está en venta o es susceptible de generar una ganancia, puede entenderse que los centros históricos han sufrido un deterioro en sus calidades de uso pero a la vez, en la medida que se prestigió la inversión en ellos, han revalorizado el valor del suelo urbano.

El centro de la ciudad comenzó nuevamente a ser interesante a los sectores que lo habían abandonado, ya sea para generar riqueza o para aprovechar las plus valías de servicios que ellos tienen.

\section{Avatares de la planificación}

En un cuadro de un Estado no solamente achicado sino debilitado en sus poderes y una economía subordinada a los "mercados", es obvio que la planificación urbana encuentra poco espacio. Ese pequeño espacio que le queda está vinculado a la línea de ordenar las inversiones urbanas atendiendo a su mayor rentabilidad.

Sin embargo ha sido tan grosera y prepotente esta actitud de los negociadores inmobiliarios y empresarios urbanos que curiosamente ha generado reacciones, no solamente en los sectores expulsados de las áreas centrales sino también en sectores medios $u$ altos que han visto deteriorarse las calidades ambientales de los lugares donde residen.

Movimientos de vecinos, comisiones barriales, organizaciones no gubernamentales, han ido generando una capacidad de respuesta, protesta y propuesta de la mayor importancia.

Los propios técnicos, de regreso de la modelística del CIAM, han comprendido la inevitabilidad del Planeamiento Participativo y han procurado capitalizar esta respuesta de la comunidad como una forma de presión orgánica dentro de las estructuras del Estado.

La figura de los "Defensores del pueblo" o las "Asociaciones de consumidores" van teniendo un papel relevante junto a los núcleos ecologistas en el control del desenfreno especulativo. Sin embargo ello no ha impedido la reducción de los mecanismos de contralor desde el propio Municipio, cuya ineficacia se proyecta ahora a las limitaciones que le imponen las restricciones económicas y políticas.

\section{El patrimonio y sus posibilidades rentables}

La recuperación del Patrimonio fue también encarada como un negocio. Es decir que la rentabilidad económica subordina a todas las demás variables incluída la propia validez del patrimonio. Este es importante en la medida en que genera esa renta y no en atención a sus propios valores intrínsecos, históricos, culturales o sociales.

Al descolocar el eje del debate, muchos edificios o conjuntos de valor patrimonial cayeron en el libre juego de la oferta y la demanda del mercado. Ya en los 70 dictaduras militares, como 
la uruguaya, habían desafectado varias docenas de edificios, que eran "monumentos históricos" protegidos por ley, para su venta y demolición.

La reducción del estado en casi todos los países del continente ha significado la venta de centenares de edificios públicos, muchísimos de ellos de valor patrimonial. El levantamiento de líneas férreas o la clausura de puertos han significado el éxodo de millares de habitantes, la desaparición de poblados y por supuesto el abandono de edificios que constituían los puntos de referencia para muchas comunidades hoy en vías de extinción.

No podemos obviamente rescatar el patrimonio y perder la gente, sin embargo este efecto de "bomba neutrónica" que salva lo edilicio y mata a lo humano, se ha aplicado mediante la expulsión de la población que allí vivía y su terciarización, o banalización para actividades lúdicas y comerciales en diversos países.

\section{Las políticas para los centros históricos en la ultima década del siglo XX}

Podemos considerar dos tipos de gestiones diferenciadas en las prácticas de intervención de los Centros Históricos Iberoamericanos en la última década.

Por un lado aquellas grandes líneas que se habían planteado con anterioridad y que continúan aún con cambios, sesgos nuevos o acentuaciones de sus modalidades. Por otro nuevas políticas o estrategias de acción que se encuadran en los cambios estructurales que ha sufrido la economía urbana.

\section{La ciudad dormitorio}

Convencidas autoridades y las elites dirigentes de ciertas ciudades de que viven sobre una verdadera "mina de oro" y amparadas en el prestigio que se instala en algunas ciudades por ser "Patrimonio de la humanidad", apuestan a llevar tal condición hasta sus últimas consecuencias y venden su ciudad.

El caso más elocuente es el de Cartagena de Indias (Colombia), un excepcional recinto amurallado que sobrevivió a la ola turística que se afincó en zonas cercanas deteriorando irremisiblemente sus otrora famosas playas. A falta de playas era menester vender patrimonio, para ello era preciso expulsar a sectores de pobladores de color y de bajos ingresos que ocupaban ciertos barrios de la ciudad, fundamentalmente en Getsemaní y San Diego.

Las estrategias comenzaron en los 70 con la demolición del antiguo mercado popular al cual llegaban las barcas de los pescadores y su reemplazo por un faraónico Centro de Convenciones. Se esperaba que la actividad diferencial que generara este nuevo polo de actividades terciarias modificaría la población y los modos de vida del sector, lo cual sucedió solo parcialmente. Políticas mas agresivas con amplias demoliciones de antiguas industrias, localización de centros comerciales y condominios residenciales, fueron cercando a la población local. 
El proyecto consistía en traer a "los ricos de Colombia" ya fuesen de Bogotá, Pereyra, Cali o Medellín a que tuviesen su casa de fin de semana y de vacaciones en Cartagena. La presunta recuperación del patrimonio actuaba como cobertura a una vasta operación de carácter inmobiliario que consistía en tomar antiguas casonas y transformarlas en varios departamentos. La imagen urbana persistía y se la notaba "enriquecida" con nuevos miradores, balcones, rejas y otros elementos que no alteraban el paisaje urbano aunque iban vaciando de contenido a la ciudad.

Los nuevos propietarios vienen a Cartagena los fines de semana, los usos cotidianos de abastecimiento y las múltiples escuelas que tenía el sector intramurallas van siendo erradicados formando una ciudad de fin de semana, que solamente mantiene la vitalidad de actividades predominantemente turísticas. Si bien se ha recuperado un uso residencial, al no ser este contínuo, ni tener los moradores relación permanente con la ciudad, distorsionan claramente la vida urbana.

La recuperación del patrimonio prescindiendo de la auténtica población trae aparejada una forma ficticia de rescate cultural, ya que se pierden los valores de referencia aunque se mantuviesen las tipologías arquitectónicas, cosa que sucede muy parcialmente como se ha dicho.

También es cierto que dado el incremento de los valores inmobiliarios en el área resulta muy difícil que una familia de recursos medios no acepte la venta de su propiedad y se traslade a otro lado. Estas son sí reglas del mercado, pero ellas aparecen hoy arropadas por los lemas de la protección del patrimonio, del rescate cultural y consiguen franquicias, líneas crediticias preferenciales y otras inversiones de recursos públicos que en la práctica están encubriendo inversiones especulativas y no sociales.

Cartagena va raudamente a convertirse, en su recinto amurallado, en una ciudad-dormitorio de fin de semana con muy probable consecuencia de ser pronto un ghetto de inseguridad con vigilancia permanente. En cualquier caso no constituye ni un rescate de un Centro Histórico ni un modo de vida digno y deseable.

\section{El rescate para el turismo}

A efectos de demostrar que los equívocos no nacen solamente de las estructuras del capitalismo, sino que también la visión economicista del marxismo aporta sus contradicciones, podemos analizar la estrategia seguida por el Gobierno cubano desde antes de la caída del muro de Berlín.

Si bien en la década del 70 el bloqueo actuaba de una manera dura sobre los intentos de rescatar el patrimonio, tanto por la imposibilidad de disponer de ciertos materiales, cuanto por la fuerte influencia de las técnicas utilizadas en la Europa del Este, los técnicos cubanos realizaban denodados esfuerzos para rescatar su patrimonio.

La inexistencia de una adecuada política de forestación, por ejemplo, dejó al país sin madera. Cuba que durante el XVIII había 
sido uno de los principales aportadores de madera para la obra del Palacio Real de Madrid, debía en el siglo XX importar madera de Angola, en extraño trueque de servicios que la "guerra fría" justificaba. La madera angoleña demostró ser mejor alimento para los xilófagos cubanos (taladros, teredos, cupí), que para su uso en restauración...

En este cuadro de situación y de carencia de divisas, el Gobierno Cubano apostó al rescate de La Habana Vieja en función, no de su población, sino del aprovechamiento turístico. Se definieron dos líneas, la que insistía, desde el Centro de Restauración, en una política de recuperación de la ciudad con usos residenciales, logrando realizar obras en la Plaza Vieja y la que, desde la Oficina del "Cronista de la Ciudad", definía intervenciones más próximas al esquema de "Ciudad Museo".

La segunda alternativa contó con el decidido apoyo del Gobierno que entregó las obras de vivienda popular en el Centro Histórico a "Microbrigadas" de empeñosos constructores-destructores, quienes expulsaron población ya radicada en la zona y trajeron a otros de fuera del Centro Histórico en una tendenciosa, manipulación de los residentes.

La inversión económica para transformación de casas de los siglos XVII y XVIII en pequeños Museos (Numismática, Cerámica etc) contradecía en la práctica estrategias como la recuperación de las Fortalezas del Morro y la Cabaña, a las cuales se "restauraba" sin tener un uso para los miles de metros cuadrados disponibles. La estrategia de la inversión turística impedía ver que hubiera sido más racional destinar estos grandes contenedores para conjuntos de museos y actividades culturales que retacear el uso residencial en el Centro Histórico.

Ideológicamente es duro tener que poner en evidencia que la política de Cuba en este aspecto en cuanto apuesta al sector turístico como fuente de desarrollo (o de sobrevivencia en este caso) no difiere demasiado de la política de Batista, postergando a los pobladores locales en beneficio de los externos. Mucho más duro parecería ser el futuro cuando las transacciones neoliberales han logrado abrir el mercado de venta de propiedades y se esperan notorias inversiones externas que pondrán finalmente en situación de lucro el patrimonio arquitectónico de La Habana Vieja.

Todo ello dicho con el reconocimiento al excepcional grupo de técnicos que desde el Centro de Restauración han venido bregando en todo el país para el rescate del patrimonio y han logrado notorios resultados en edificios puntuales o en poblados históricos como Trinidad y Camagüey.

\section{El rescate cultural}

Encubiertas en campañas de rescate cultural se han realizado intervenciones desde el Estado que han en la práctica generado distorsiones en los Centros Históricos. Ya hemos hecho referencia al caso de Santo Domingo donde se generaron áreas enteras de "la ciudad romántica" como la llamó el Presidente Balaguer bajo cuyos múltiples mandatos se han hecho estas obras. 
En estas campañas colombinas han colaborado notoriamente "restauradores" españoles con la fabricación de arcos de cantería y blasones diversos que se han colocado en monumentos americanos. La ola de "hispanidad" que alcanzó relieve con los asesoramientos militares del Coronel Zapatero, nos dejó cañones de cemento en múltiples fortalezas, así como trofeos, banderas y maniquíes similares en cantidad de museos de sitio (Casa de Benalcázar, Quito, Ecuador, Casa de la Independencia, Asunción, Paraguay, Fortaleza de Santa Teresa, Uruguay etc). Esta igualación museística por la réplica, más allá del buen negocio de los fabricantes, ha quitado personalidad y carácter al propio patrimonio, sin referirnos claro está a la falsificación histórica que esconden varias de estas reproducciones.

Un caso de mayor envergadura es sin duda el sucedido en el Pelourinho de la ciudad de Salvador (Bahia, Brasil). Habíamos hecho referencia a los intentos de rescate desde una perspectiva que posibilitara la integración de la población de bajos ingresos que allí habitaba. En la época de Collor de Mello, un gobernador conservador comenzó una estrategia de expulsión de la población, negociación con los propietarios de viviendas, líneas de crédito para la instalación de comercios y sobre todo altas inversiones en seguridad en el esquema: un turista $=$ un policía.

Los impedimentos legales que existían para la anterior política, tales como propiedades que no se podían vender pues pertenecían a sociedades que habían recibido la donación con cargo de mantener el bien, fueron de golpe destrabadas por la presión y la decisión política que arbitró modos de compra enfiteútica y realizó inversiones de recursos oficiales en bienes que no eran del Estado.

Se expulsó a la población de bajos ingresos, algunos con varias décadas de residencia en el lugar, y se produjeron demoliciones, reconstrucciones, vaciamiento de centros de manzana, creación de nuevos espacios abiertos y el montaje de un gran espectáculo publicitario que daría la nueva imagen de un gobierno preocupado por "la cultura bahiana".

En la primera fase la experiencia fue exitosa, los turistas volvieron al amparo de una seguridad que les garantizaba recorrer la zona sin asaltos y sin ver pobres (oportunamente trasladados a los lugares específicos para pobres). También los residentes de Bahía, de sectores medios y altos, sobre todo jóvenes, ocuparon la zona para sus encuentros nocturnos. Sin embargo la presencia de números musicales con conjuntos regionales fue dividiendo y caracterizando las distintas zonas e inclusive los distintos días, fragmentando los territorios de los blancos y de los negros.

Si el área ganó en dinámica de uso, el patrimonio sufrió daños irreparables por la ruptura de las líneas municipales, demoliciones innecesarias, falsificaciones posmodernistas y una suerte de banal forma de re-creación del patrimonio. la calidad de las obras, hechas a medida de la farsa cultural, aseguran una rápida decadencia una vez que la "moda" pase y este centro histórico, obliterado y mutilado, quede. 


\section{Las obras de impacto}

Una de las formas de recuperación de Centros Históricos ha sido la de generar obras de gran volumen e impacto urbano, generalmente a escala de la ciudad y no del propio centro histórico. Esto en sí mismo sería una estrategia acertada si consideramos al Centro Histórico como un barrio más de la ciudad cuya especificidad es justamente el que representa a toda ella, o que todos sus habitantes lo reconocen como referente de la misma.

Lo que no está tan bien es que generalmente estas obras en un Centro Histórico implican poco respeto al monumento o la obra que sirve de base a la inversión porque en definitiva lo que interesa es la inversión misma. Si bien es cierto que estas obras en algunos casos han permitido recuperar edificios que probablemente se hubieran destruido si no se actuaba en ellos, también podemos afirmar que las intervenciones pudieron haber sido mas respetuosas desde el punto de vista del patrimonio. Obras como las Galerías Pacífico o el centro Cultural de la Recoleta en Buenos Aires no han tenido el cuidado que es posible verificar en otras intervenciones como la de la Estación Mapocho en Santiago de Chile o inclusive en la antigua Cervecería Bavaria en Bogotá.

\section{Los reciclajes}

El tema anterior nos lleva justamente a los problemas de reciclajes de grandes contenedores urbanos, hospitales, almacenes, cuarteles, puertos, industrias, que han quedado obsoletos en su uso original pero cuya capacidad edilicia no está agotada. En muchos casos se trata de obras de valor patrimonial y de importancia referencial para las comunidades de su zona o barrio ya que no siempre están propiamente en el centro Histórico de la ciudad que, generalmente, ocupa las áreas centrales y con edificación más convencional.

En general las estrategias han sido fundamentalmente de vaciamiento de los edificios, dejando sus fachadas perimetrales y trabajando "libremente" dentro de ellos para colocar "Lofts", "Shopping centers", "Dormy houses" y algún eventual uso menos sofisticado. La generalización de este tipo de intervenciones sin contralor ha determinado que muchos confundan hoy restauración con rehabilitación, refuncionalización o reciclaje y quien ha perdido en la confusión es, sin dudas, el patrimonio.

\section{Alternativas y posibilidades}

\section{La negociación de la ciudad}

Quizás el ejemplo mas notorio, en dos etapas, ha sido la negociación del centro histórico y las áreas centrales de la ciudad de México. Luego del terremoto de 1985, la presión de miles de personas viviendo en la calle por la destrucción de sus viviendas, puso en juego la organización y participación popular que obligó al Gobierno a expropiar no menos de 4000 predios en el Centro Histórico y zona central de México.

Puso esta circunstancia en evidencia la potencialidad de las fuerzas populares, el apoyo de los organismos universitarios y técni- 
cos y la dinámica del apoyo económico ante la emergencia. En año y medio se realizaron más de 40.000 unidades de vivienda, entre operaciones de reciclaje, rehabilitación, restauración y nueva planta con activa participación de los pobladores en la autoconstrucción dirigida.

Este proceso demostró que, en la emergencia y ante la protesta popular, aparecen los recursos y las decisiones políticas para dar respuestas y calmar las demandas. ¿No sería interesante no tener que esperar un catastrófico terremoto para dar solución a estas carencias de vivienda secularmente postergadas?

La segunda fase corresponde a la etapa posterior donde técnicos con conciencia y poder suficiente posibilitaron una forma de "negociación" de la ciudad para la ciudad. Las presiones inmobiliarias en distintas zonas del Distrito Federal fueron canalizadas a dejar respuestas adecuadas en el área histórica.

Los trámites de excepciones en otras áreas (mayor perímetro o altura) debían de esta forma ser compensadas con inversiones en restauración o reciclaje de edificios en el Centro Histórico. De la misma manera desde el Estado se cedieron edificios o tierra urbana a instituciones de bien público con el compromiso de restaurar, mantener o construir edificios contextualizados.

Un total de casi 800 obras demostraron que era posible la negociación de la ciudad frente a las presiones y a la vez marcaron índices de fuerte recuperación de edificios. No siempre las actuaciones de los arquitectos de mayor prestigio fueron compatibles con la arquitectura histórica, pero no cabe duda de que la huella de esta generación de profesionales quedará marcada en el Centro Histórico de México.

Una agresiva política de compra por sectores privados de los edificios del Centro Histórico caracterizó también una nueva fase de esta política de priorizar esta área urbana en la inversión de la economía inmobiliaria.

\section{Planeamiento participativo}

Un ejemplo interesante de planeamiento desde la función municipal, con técnicos comprometidos en el rescate del patrimonio, lo podemos encontrar en el caso de Montevideo (Uruguay).

La gestión municipal planteó para la ciudad, conformada privilegiadamente por barrios, estructuras vecinales de participación ("Consejos") que aseguraron una correcta trasmisión de las expectativas y potencialidades de los vecindarios locales.

La "Ciudad Vieja" que contaba desde la década del 80 con una Comisión de protección había logrado una buena dinámica en materia de restauración, pero logró mediante apoyos políticos implementar líneas crediticias para rehabilitación de edificios lo que desató una fuerte inversión en el Centro Histórico.

La adecuada articulación entre vecindario, profesionales, organismos técnicos nacionales y municipales a dado como resultado la modificación de la curva de decadencia que caracterizara a la ciudad durante la dictadura militar, en que llegó a tener (demoliciones especulativas mediante) un $12 \%$ de su suelo urbano baldío. 


\section{Conducción consensuada}

En este caso podemos señalar el legítimo orgullo que tiene el habitante de Curitiba (Paraná, Brasil) por su ciudad. Fruto de una modalidad de planificación participativa y consensuada, formada desde el Plan Director de 1965, la ciudad pudo desarrollarse gracias a la continuidad de la gestión profesional del Alcalde Jaime Lerner durante más de doce años.

En la actualidad el arquitecto Lerner ha sido elegido Gobernador del Estado por el prestigio de su sólida acción municipal donde, junto a los innovadores sistemas de transporte y la preocupación ecológica, el patrimonio ha tenido particular incidencia.

El consenso con los agentes económicos urbanos se logró mediante la implementación de formas de compensación de espacios aéreos, derechos por restricciones al dominio en edificios declarados de interés patrimonial (700) y sobre todo por la activa participación del municipio en el mercado de tierras que le permitió negociar las formas de expansión de la ciudad.

La inducción de líneas de crecimiento, la capitalización por la comunidad de la plus valía generada por las acciones del municipio, indican la vigencia de una planificación efectiva lograda con el decidido apoyo de los habitantes de Curitiba.

A ello podemos agregar el exitosos sistema de transporte urbano de Curitiba que ya ha sido aplicado con señalado éxito en Bogotá y México y con notorias dificultades en el caso de Santiago de Chile.

\section{La acción convencida desde el poder municipal}

Las gestiones municipales desde Rodrigo Paz en Quito (Ecuador) pueden señalar, con estilos diferentes, el común interés del patrimonio cultural y el rescate del centro histórico como prioridad en sus políticas.

Para ello se implementó en la gestión de Paz el llamado "Fondo de Salvamento" de Quito, que atendió preferencialmente los monumentos dañados en el sismo de 1987. Posteriormente esta línea de acción que contó con apoyo no solamente público, sino también privado permitió el rescate de muchos edificios singulares destinados a usos comunitarios, tanto culturales cuanto sociales.

La preocupación por la recuperación de calidades y actividades en los espacios públicos fue otra de las líneas jerarquizadas en ambas gestiones donde, más allá de las desparejas calidades de las obras, se obtuvo una dinamización y reordenamiento de usos de los espacios.

La presencia de un equipo técnico, con profesionales de solvencia, una hábil captación de recursos internacionales de la cooperación y el legítimo orgullo de los habitantes de Quito por su ciudad fueron elementos movilizadores de estas operaciones que revirtieron espectacularmente el proceso de deterioro que se venía planteando. 
Aún quedan grandes problemas pendientes como el vaciamiento residencial del área central y el impacto que el comercio ambulante del sector informal crea en el Centro Histórico. Estos problemas comunes a varios de los centros iberoamericanos, se ha buscado resolverlos mediante la construcción de mercados periféricos (Arequipa. Perú), mercados populares en zonas próximas (Lima, Perú) o simplemente con un reordenamiento controlado (México, Quito etc). En todos los casos constituye hoy un tema central dentro de una realidad urbana y social que ha llevado a esta economía informal de subsistencia, a buena parte de los habitantes de las ciudades y su región inmediata.

Un proyecto interesante que vinculó a la gestión municipal de Buenos Aires con la Cooperación internacional de España fue el de la recuperación de la Avenida de Mayo. Si bien se trataba de una intervención más escenográfica que actuaba sobre las fachadas de los edificios, la gestión ante centenares de propietarios e inquilinos dejó una valiosa experiencia participativa y demostró la viabilidad de este tipo de operativos. Los cambios de gobierno municipal lamentablemente le quitaron la convicción inicial al proyecto, justamente cuando la recuperación externa de las fachadas y las plantas bajas de un prolongado tramo de la Avenida, estaba abriendo puertas a otras intervenciones internas y estructurales por parte de los propietarios.

\section{Rehabilitación de vivienda}

En esta última década se ha podido finalmente implementar algunas intervenciones de rehabilitación de patrimonio para vivienda popular tomando para ello antiguos conjuntos residenciales tugurizados y dándoles las calidades de vida necesarias.

No se trata de trabajos de restauración sino de recuperación de edificios que requerían consolidaciones estructurales, cambios de aberturas, estructuración de servicios sanitarios y de cocina, lavaderos comunes y otras formas mas racionales de utilización de los espacios.

En la experiencias realizadas en Sudamérica ha tenido particularísima importancia la Cooperación internacional realizada por la Consejería de Obras Públicas y Vivienda de la Junta de Andalucía, que fue la primera, bajo la gestión del arquitecto José Ramón Moreno y el sociólogo Luis González Tamarit, en plantear planes de ayuda para rehabilitación de vivienda popular en edificios de valor patrimonial.

La tarea efectuada en la "Casa Verde" en Montevideo, la "Casa de los siete patios" en Quito, el "Conventillo de San Francisco" en Buenos Aires y la "Comunidad Andalucía" en Santiago de Chile recogen la viabilidad de este camino para rescatar patrimonio y resolver a la vez problemas sociales.

Esta forma de intervención en el patrimonio sigue siendo de fundamental importancia, pero es difícil vislumbrar como será posible que ella se desarrolle en el futuro cuando la mayoría de los países actuantes bajo el sistema del neoliberalismo político han cancelado casi todas las líneas de financiamiento para 
vivienda popular y reducido a su mínima expresión los organismos técnicos que implementaban este tipo de planes.

La dureza de estas políticas está trayendo como contrapartida el creciente proceso de intrusismo, ocupación e invasión de casas vacías en áreas centrales de las ciudades (Buenos Aires, Montevideo, Lima etc). Ello exacerba los conflictos urbanos en los centros históricos. No es posible repensar estas zonas de la ciudad con el retorno de los sectores que las abandonaron en busca de mejores calidades de vida.

Tampoco sería justo que la sociedad toda pagara la recuperación de esas calidades en las áreas centrales para dárselas justamente a quienes las abandonaron y tienen recursos para construirse un hábitat mejor. No hay de todos modos demasiadas esperanzas para los ocupantes ilegales, los marginales de la ciudad o los vecinos que las habitan y carecen de recursos.

Si el centro histórico se recupera al estilo Salvador (Bahia, Brasil) el lugar de los pobres lugar estará en la periferia, si se mantiene en este grado de conflicto estabilizado no hay esperanza para el Centro Histórico y su patrimonio. Cabe preguntarse: ¿Es justo tener que elegir entre el patrimonio y la gente? ¿No podemos salvar el patrimonio con su gente?.

Un centro histórico casi desahuciado como Lima tiene el $45 \%$ de la propiedad de la tierra urbana en manos del Estado, el Municipio, la Iglesia, el Ejército y la Universidad, y el $15 \%$ son terrenos vacíos. ¿No es posible soñar una acción del Estado que construye ese $15 \%$ baldío con viviendas populares, que construya centros de servicios en los vecindarios del norte de la ciudad y libere en parte el uso del área central, que en definitiva piense que el patrimonio de la ciudad son sus edificios pero principalmente sus habitantes?

Necesitamos cada vez más un espacio para la utopía, pero también gobernantes comprometidos con su cultura y su compromiso social.

\section{Referencias}

GUTIÉRREZ, Ramón (Coord.). El centro histórico de La Habana Vieja: un futuro para el pasado. Madrid: El Viso, 2004.

GUTIÉRREZ, Ramón (Coord.). Los centros históricos de América Latina. Bogotá: Escala, 1984.

GUTIÉRREZ, Ramón (Coord.). Pueblos de indios: otro urbanismo de la región andina. Quito: Biblioteca Abya-Yala, 1993.

GUTIÉRREZ, Ramón. Arquitectura y urbanismo en lberoamérica: siglos XVI al XX. Madrid: Cátedra, 1983.

GUTIÉRREZ, Ramón; OSWALDO Enrique. Patrimonio arquitectónico y centros históricos en América Latina: recursos humanos, requerimientos y oportunidades de trabajo. Lima: Convención del Patrimonio Mundial, 1984.

HARDOY, Jorge Enrique et al. El centro histórico de Quito. Quito: Banco Central del Ecuador, 1984.

HARDOY, Jorge Enrique et al. El centro histórico del Cuzco. Lima: Banco Industrial del Perú, 1983. 
INSTITUTO ANDALUZ DEL PATRIMONIO HISTÓRICO. Indicadores para la evaluación del estado de conservación de ciudades históricas. Sevilla: Instituto Andaluz del Patrimonio Histórico, 1999.

\section{Endereço para correspondencia}

Ramón Gutiérrez

Junín $11405^{\circ} \mathrm{B}$

1113- Buenos Aires - Argentina

ramongut@interserver.com.ar 